\title{
A STUDY OF ACUTE MYOCARDIAL INFARCTION IN YOUNG ADULTS WITH REFERENCE TO OCCUPATION
}

\author{
Poongavanam Paranthaman'1, Thenrajan Balaji2, Ponnuswamy Raja³, Jayakrishnan Jeyakumar 4
}

1 Professor, Department of General Medicine, Government Royapettah Hospital, Kilpauk Medical College.

${ }^{2}$ Assistant Professor, Department of General Medicine, Government Royapettah Hospital, Kilpauk Medical College.

${ }^{3}$ Assistant Professor, Department of General Medicine, Government Royapettah Hospital, Kilpauk Medical College.

${ }^{4}$ Assistant Professor, Department of General Medicine, Government Royapettah Hospital, Kilpauk Medical College.

\section{ABSTRACT}

\section{BACKGROUND}

Acute myocardial infarction is one of the most common diagnosis in hospitalised patients, the typical patient with myocardial infarction is a man more than 50 years and a woman more than 60 years of age who presents with severe retrosternal chest pain which is squeezing, heaviness, choking or smothering radiating to left shoulder or jaw. We recently observed that acute myocardial infarction occurs in much younger age, more common in people with history of driving auto rickshaw in Chennai city. We know that risk factors for myocardial infarction are smoking, hypertension, diabetes, dyslipidaemia, obesity, inactivity, etc. but we do not know whether any particular occupation is a risk factor for myocardial infarction. We recently observed that more admissions in ICCU in our hospital with myocardial infarction are young males with history of driving auto rickshaw in the Chennai city for many years.

This study aims to find the incidence of acute myocardial infarction in young adults in Chennai city in relation to different occupations.

\section{MATERIALS AND METHODS}

This study was conducted at the ICCU, Government Royapettah Hospital and Institute of Non-Communicable Diseases, Chennai between May 2009 and December 2010. It included 612 patients admitted with Acute Myocardial Infarction. The diagnosis was based mainly on the clinical symptoms and signs such as retrosternal chest pain, sweating and radiation to the shoulder and jaw with breathlessness and the ECG findings such as ST segment elevation more than $1 \mathrm{~mm}$ in limb leads and more than $2 \mathrm{~mm}$ in chest leads. We categorised them according to the age and occupation and analysed the statistical significance with reference to Chisquare test.

\section{RESULTS}

Out of the 612 patients studied, distribution among various occupations was as follows: 1. Auto driver: 97 (15.8\%). 2. Watchman: 40 (6.5\%). 3. Manual Labourer: 77 (12.6\%). 4. Self-employed: 74 (12.1\%). 5. Office worker: 64 (10.5\%). 6. Housewife: 70 (11.4\%). 7. Unemployed and pensioners: 190 (31\%).

Chi-Square test $P$ value: 0.00 .

Likelihood ratio: 0.00 .

Linear by linear association: 0.00 which is statistically highly significant.

\section{CONCLUSION}

There is a progressive increase in incidence of myocardial infarction as age advances in all occupations except in auto drivers where the peak incidence is at the age group 35 to 45 years (33/132) which constitutes $25 \%$ of acute myocardial infarction in that age group which is statistically highly significant.

\section{KEYWORDS}

Myocardial Infarction, Young Adults, Occupational Risk.

HOW TO CITE THIS ARTICLE: Paranthaman P, Balaji T, Raja P, et al. A study of acute myocardial infarction in young adults with reference to occupation. J. Evolution Med. Dent. Sci. 2017;6(9):727-729, DOI: 10.14260/Jemds/2017/156

\begin{tabular}{l}
\hline BACKGROUND \\
Recently, we observed increased incidence of myocardial \\
\hline Financial or Other, Competing Interest: None. \\
Submission 07-12-2016, Peer Review 15-01-2017, \\
Acceptance 21-01-2017, Published 30-01-2017. \\
Corresponding Author: \\
Dr. Poongavanam Paranthaman, \\
Professor, \\
Department of General Medicine, \\
Government Royapettah Hospital, \\
Kilpauk Medical College, \\
Chennai-600014. \\
E-mail: paranthaman1964@rediffmail.com \\
DOI: $10.14260 /$ jemds/2017/156 \\
CC) $\$$ (1)
\end{tabular}

infarction in young adults when compared to middle aged and older population as found in the past.

There are several studies which reported that the myocardial infarction risk is higher in professional drivers. ${ }^{[1]}$ A recent Swedish investigation indicated that bus driving in urban areas is associated with an increased risk of myocardial infarction, although no increased risk was found among bus drivers in rural areas. ${ }^{[2]}$ The common risk factors for myocardial infarction like tobacco smoking, hypertension, dyslipidaemia, diabetes, in addition to the hereditary factors and obesity play a part in assessing the risk of developing myocardial infarction[3]. Further, low physical activity at work or during leisure time, cold, and heat has been proposed as risk factors for myocardial infarction. Exposure to smoke in a traffic which contain certain chemicals has been 
associated with increased risk of myocardial infarction. ${ }^{[4]}$ It is not known if this increased risk is due to any specific chemical such as carbon monoxide or polycyclic aromatic hydrocarbons (PAHs), and neither is it known if exposure to motor exhaust is of relevance for the increased risk of myocardial infarction among professional drivers. Among the drivers, the job stress and the high psychological demands has been proposed as risk factor for myocardial infarction.

\section{MATERIALS AND METHODS}

This study was conducted in the ICCU, Government Royapettah Hospital and Institute of Non-Communicable Diseases, Chennai between May 2009 to December 2010. It included 612 patients admitted with Acute Myocardial Infarction. The diagnosis of myocardial infarction was made based on the clinical symptoms and signs at the time of admission and the ECG changes such as ST elevation

\section{RESULTS}

In our study, total number of patients were 612 of which 532 (86.9\%) were male, 80 (13.1\%) were female (Fig. 1). We categorised them according to the occupation in the order of frequency.

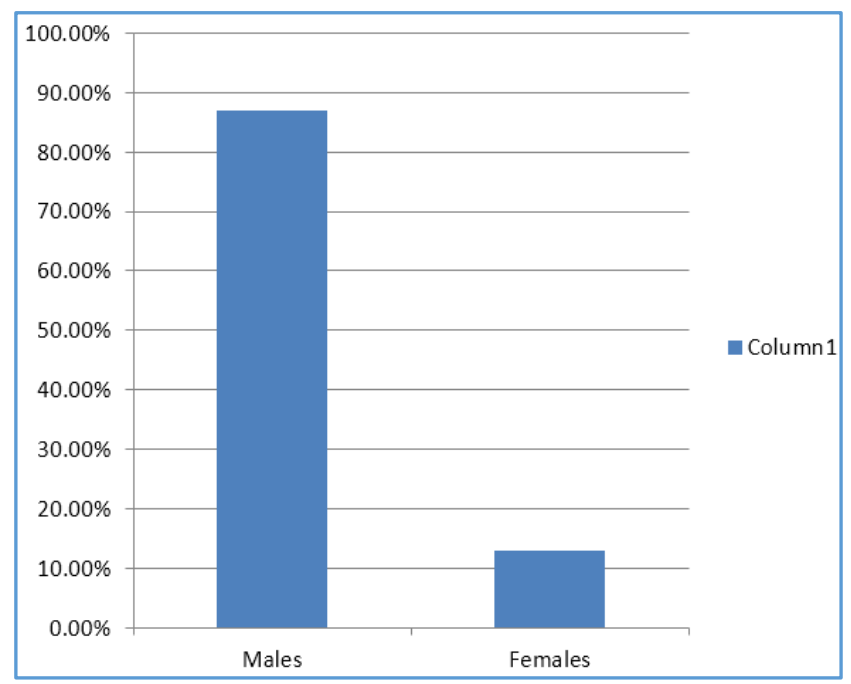

Figure 1. Gender wise Distribution of Myocardial Infarction

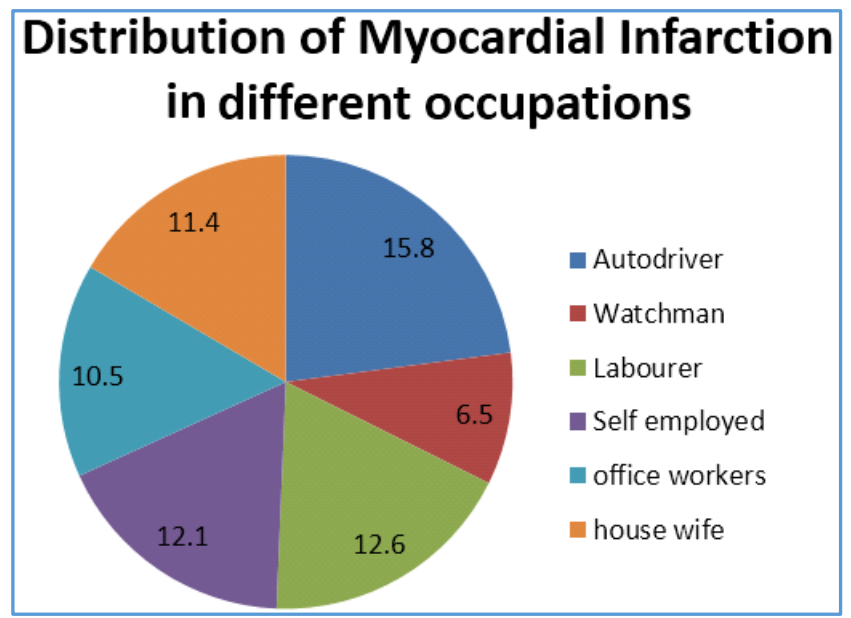

Figure 2. Myocardial Infarction in Different Occupations
Auto drivers: 97 (15.8\%). 2. Watchman: 40 (6.5\%). 3. Labourer: 77 (12.6\%). 4. Self-employment: 74 (12.1\%). 5. Office worker: 64 (10.5\%). 6. Housewife: 70 (11.4\%). 7. Unemployed, pensioners and others: 190 (31\%).

\section{Distribution of Myocardial infarction in young adults in different occupations}

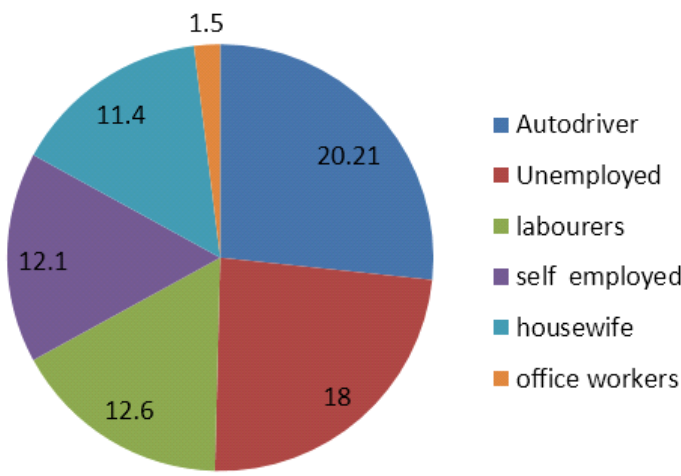

Figure 3. Myocardial Infarction in Different Occupations in Young Age

Total number of patients less than 45 years were 183 (29.9\%) of which 37 (20.21\%) were auto drivers, unemployed 32 (18\%), labourers 23 (12.6\%), selfemployment 22 (12.1\%), housewife 21 (11.4\%), office workers 19 (1.5\%), watchman 11 (6.5\%), pensioners and others 18 (9.8\%) (Fig. 3).

We categorised them according to the age wise distribution in different occupations and found that the incidence of myocardial infarction increases as the age advances in all occupations except auto drivers. In them more myocardial infarctions were observed in the young age, 35-45 years (20.21\%), which is statistically significant (Fig. 4).

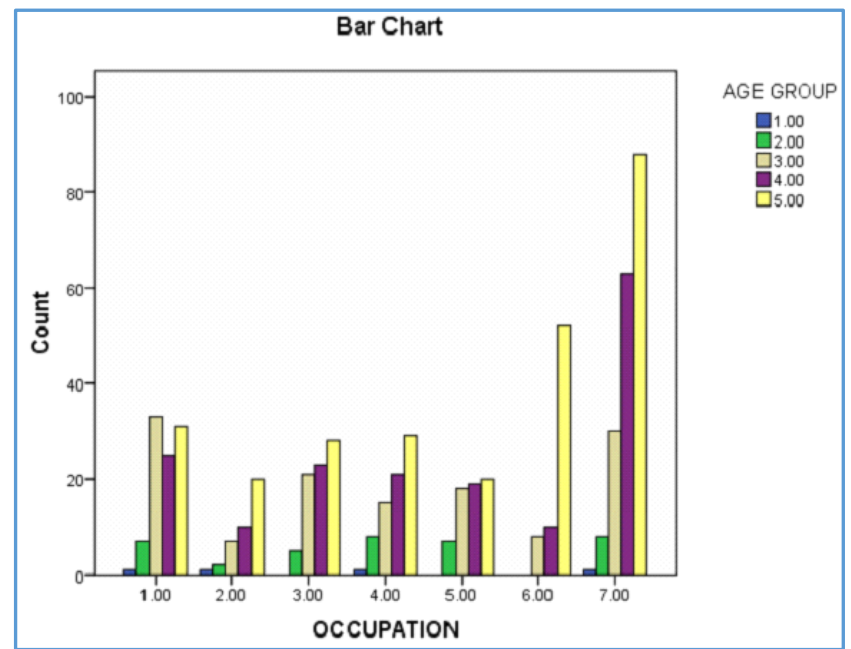

Figure 4. Myocardial Infarction in Different Occupations with Age wise Distribution 


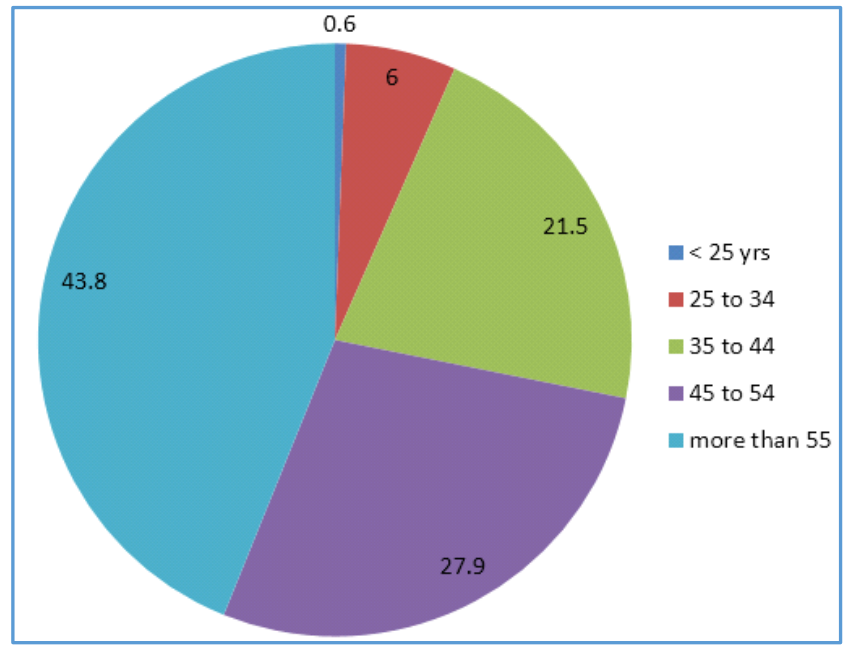

Figure 5. Age wise Distribution of Myocardial Infarction

Chi-Square test $P$ value: 0.00 .

Likelihood ratio: 0.00 .

Linear by linear association: 0.00 .

Which is statistically highly significant.

\section{DISCUSSION}

In our study, overall there is an increased incidence of myocardial infarction in young age, 183 out of 612 (29.9\%) as compared to middle and old age in all occupations, may be related to the life style changes like lack of physical activity and excess caloric intake in addition to the other risk factors like smoking, hypertension, dyslipidaemia. We also observed that there is an increased frequency of acute myocardial infarction as age advances in all occupations except in auto rickshaw drivers in whom myocardial infarction was higher in the age group less than 45 years than the other occupations, this may be related to exposure to smoke, chemicals, lack of physical activity, working for long hours of the day, psychological stress due to stress of traffic in busy city of Chennai in addition to the other risk factors like smoking habits, dyslipidaemia, diabetes, hypertension, obesity which was almost same as that of other occupations. Our observations are similar to other studies quoted in the reference. In our study, we found that there is an overall increase in myocardial infarction in young auto rickshaw drivers in the age group 35 to 44 years which accounts for 37 out of $183(20.21 \%)$ followed surprisingly by unemployed 32 out of $183(18 \%)$ which may be due to stress of economic burden in the city to meet out the daily needs of family in addition to other risk factors like smoking, diabetes, hypertension and dyslipidaemia and physical inactivity, followed by labourers 23 out of 183 (12.6\%) primarily due to lifestyle changes. The self-employment was the next which accounts for 22 out of $183(12 \%)$, this may be attributed to the stress of competitive business in the city. Surprisingly, the myocardial infarction in housewives in young age has also increased in our study which accounts for 21 out of 183 (11.4\%), followed by office workers 19 out of $183(10.3 \%)$, watchman 11 out of 183 (6.5\%), pensioners and others 18 out of $183(9.8 \%)$ which could be due to less physical activity and the stress of managing family in the city life. The myocardial infarction in younger age is less common among watchman, this may be due to less commitment and relaxed life. In our study, we have observed that there is an overall increased incidence of myocardial infarction in young age. It was also observed that this was more among the young auto rickshaw drivers in the Chennai city, therefore we should take measures to prevent this occurrence by primary prevention in the form of health awareness camps and health education to prevent morbidity and mortality due to coronary artery diseases.

\section{CONCLUSION}

There is a progressive increase in incidence of acute myocardial infarction as age advances except in auto rickshaw drivers where the peak incidence is in the age group of 35-44 years which constitutes $25 \%$ of myocardial infarction in that age group (Figure 4) which is statistically significant. This explorative study gives some support to the hypothesis that occupational exposure particles increase the risk of acute myocardial infarction in addition to smoking, diabetes, dyslipidaemia, and hypertension and other risk factors and also the psychosocial work conditions may play a part in increased incidence of myocardial infarction and should be investigated further.

\section{REFERENCES}

[1] Alfredsson L, Hammar N, Hogstedt C. Incidence of myocardial infarction and mortality among bus drivers in Sweden. Int J Epidemiol 1993;22(1):57-61.

[2] Michaels D, Zoloth SR. Mortality among urban bus drivers. Int J Epidemiol 1991;20(2):399-404.

[3] Tuchsen F, Bach E, Marmot M. Occupation and hospitalization with ischaemic heart diseases: a new nationwide surveillance system based on hospital admissions. Int J Epidemiol 1992;21(3):450-9.

[4] Kristensen TS. Cardiovascular diseases and the work environment. A critical review of the epidemiological literature on chemical factors. Scand J Work Environ Health 1989;15(4):245-64. 